\title{
Retardate trace classical conditioning with pure tone and speech sound CSs
}

\author{
MARGARET M. GUMINSKI and LEONARD E. ROSS \\ University of Wisconsin, Madison, Wisconsin 53706
}

\begin{abstract}
Retardate trace conditioning performance with a 200-msec trace CS and a 450-msec CS-offset/UCS-onset interval was compared under pure-tone (slow and fast rise-time) and speech sound (a synthesized voiced stop consonant-vowel) conditions. There was no effect of type of CS, but the retardates showed a bimodal performance distribution atypical for single-cue conditioning. Additional data collected under the same CS and ISI conditions with normal subjects demonstrated an essentially unimodal performance distribution again with no effect of type of CS presented.
\end{abstract}

It has been demonstrated that retarded subjects show a trace deficit in classical eyelid conditioning compared to normals of the same CA if the interval from CS offset to UCS onset exceeds a critical value (e.g., Ross, 1972; Ross \& Ross, 1975). One factor that might be of importance relative to this deficit is the type of CS employed. Prior trace eyelid conditioning involving the retarded has utilized pure-tone CSs, and there is a possibility that stimuli such as speech sounds might be more effective as the CS in trace conditioning. Research on the perception of speech sounds has suggested that these stimuli are processed differently than are other auditory stimuli (e.g., Mattingly, Liberman, Syrdal, \& Halwes, 1971). Such differences might make them more effective in bridging the interval from CS offset to UCS onset resulting in better trace conditioning on the part of the retardates.

One aim of the present study thus was to investigate the retardate trace-conditioning deficit by comparing retardate trace-conditioning performance under pure-tone and speech sound CS conditions. A second objective was to compare the general level and distribution of retardate and normal conditioning performance. Although the classical eyelid conditioning performance of normals is very similar under trace and delay conditions (Ross \& Ross, 1971), normal subject groups were added to the present study for comparison purposes when it became apparent that the retarded subjects showed a bimodal performance distribution atypical for single-cue conditioning.

\section{METHOD}

\section{Subjects}

The subjects were 24 severely and profoundly retarded residents

This research was supported by Public Health Service Research Grant No. HD 05653 from the National Institutes of Child Health and Human Development. The authors thank Philip Morse for providing the speech sound stimulus and Susan M. Ross for her assistance. of Central Wisconsin Colony and Training School and 48 college sophomores at the University of Wisconsin-Madison. All retarded subjects ( 11 males and 13 females, CA 15 years 5 months to 24 years 1 month) were free of any gross vision or hearing losses, as indicated by their medical records, were receiving very limited amounts of medication or no medication, and were selected for their cooperativeness and their ability to sit upright in a chair.

One-half of the subjects in the normal comparison group were randomly selected from summer-session student class lists and were paid for their services. The remaining one-half of the subjects were students in introductory psychology who were given the option of participating in experiments in order to earn additional class points. There were equal numbers of paid and point subjects in each experimental group.

\section{Apparatus}

The retardate data was collected in a two-room laboratory suite located at Central Wisconsin Colony. The equipment for generating the auditory stimuli and recording the eyelid response (see Wilcox \& Ross, 1969 for a description of this equipment) was located in one of the rooms, and the subject was seated in the other. Cne experimenter romained with the subject throughout testing while a second experimenter monitored the equipment in the adjacent room. The normal subjects were tested in a three-room laboratory consisting of two mirror-image experimental rooms and an adjoining room containing the apparatus for the production and control of the auditory stimuli (see Nelson \& Ross, 1974, for a description of this equipment).

Three pure-tone $(800-\mathrm{Hz})$ and one voiced stop consonant-vowel stimulus, /ba/, which was synthesized on the Haskins Laboratories' parallel resonance synthesizer, were utilized as CSs. The two formants of the speech sound began together, the second formant transition lasting for $25 \mathrm{msec}$. The speech sound had a "slow" rise time (approximately $25 \mathrm{msec}$ ) while each of the pure tones had either a "slow" or a "fast" (approximately 10 microsec) rise time.

Earphones were used to present the 65-dB white-noise background and the 85-dBA stimuli. The CS durations for all stimuli were $200 \mathrm{msec}$ and the ISI was $650 \mathrm{msec}$.

The UCS was a puff of compressed air to the right cornea with an intensity of 1 psi and a duration of $100 \mathrm{msec}$. Intertrial intervals of 15,20 , and $25 \mathrm{sec}$ with a mean of $20 \mathrm{sec}$ were employed.

\section{Design}

The experiment involved single-cue trace conditioning in a between-subjects 2 by 4 factorial design consisting of two subject groups (retardates and normals) and four types of auditory CSs (one slow and two fast rise-time pure tones and a synthesized speech sound). The speech sound, the slow rise-time tone and one of the fast rise-time tones were recorded on a Sony 850 tape recorder and 
played on a Sony 770 recorder while an oscillator was utilized to generate and present the remaining fast rise-time tone.

The four retardate groups, six subjects per group, contained approximately equal numbers of males and females and were matched as to CA. The groups were also matched as to mean MA although individual MA scores were of questionable reliability and comparability due to the low functioning of the subjects and the fact that several different evaluative tests were used. Ten of the subjects had participated in previous trace classical conditioning studies but with trace interval durations at which retardates would not be expected to condition (Ross, 1972). These subjects were randomly assigned to CS conditions such that there were three in the speech sound group. three in the slow rise-time group, and four in the fast rise-time tape group. An analysis comparing the final level of conditioning performance reached by these 10 subjects in previous studies with their performance in this experiment yielded a nonsignificant correlation coefficient of -.23 , indicating no important relationship between their past and present conditioning performance.

The four normal groups, 12 subjects per group, contained equal numbers of males and females and were of the same approximate $\mathrm{CA}$ as the retardate groups.

\section{Procedure}

During the conditioning session, each retarded subject was seated in his own wheelchair or in a plastic chair of the type used in Central Wisconsin Colony dining rooms. Throughout the session, silent Walt Disney color cartoons were shown on a screen in front of the subject in order to maintain the subject's attention and cooperation. The subjects did not receive any formal instructions prior to conditioning.

The retarded subjects were conditioned for 5 consecutive days with 50 trials per day, resulting in a total of 250 conditioning trials. During the first conditioning session, each subject received three initial trials, two with the CS alone and one with the UCS alone, followed by 50 single-cue conditioning trials. On Days 2-5, the three pretrials were omitted.

All normal subjects received 50 trials of trace single-cue conditioning in one experimental session. Prior to the conditioning trials, the subjects were given the three pretrials as described above and were requested not to aid or inhibit their natural reactions. Silent films were shown to the normal subjects during the session.

\section{RESULTS}

An analysis of variance performed on percentage CRs on Day 5 for the retardates and on the last block of 10 trials for the normals revealed a significant effect of population (retardate-normal), $F(1,64)=17.91$, $\mathrm{p}<.001$, but nonsignificant effects for both the type of CS received, $\mathrm{F}(3,64)=.67$, and the interaction of Population by Type of CS, F $(3,64)=.147$. Table 1 presents the mean percent CRs given on Day 5 by the retarded subjects and the mean percent CRs given on the last block of 10 trials by the normal subjects for the four types of CSs.

Separate two-factor analyses of variance with one between-subjects factor (type of CS) and one within-subjects factor (days for the retarded subjects and trial blocks for the normal subjects) were carried out for the two population groups. For the retardate groups, the analysis yielded a nonsignificant $\mathrm{F}$ for the type of CS condition, $F(3,20)=.249$, as well as for the interaction of Type of CS by Days, $F(12,18)=.586$. The main effect of days was significant,
Table 1

Mean Percentage of Conditioned Responses on Day 5 for the Retarded Subjects and for 50 Conditioning Trials for the Normal Subjects as a Function of Type of CS Condition

\begin{tabular}{|c|c|c|c|c|}
\hline & & $\begin{array}{c}\text { Slow Rise } \\
\text { Time }\end{array}$ & $\begin{array}{l}\text { Fast Rise } \\
\text { Time }\end{array}$ & $\begin{array}{c}\text { Fast Rise } \\
\text { Time }\end{array}$ \\
\hline & $\begin{array}{l}\text { Speech } \\
\text { Sound }\end{array}$ & Pure-Tone & Tone-Tape & $\begin{array}{c}\text { Tone- } \\
\text { Oscillator }\end{array}$ \\
\hline $\begin{array}{l}\text { Retardates } \\
\text { Normals }\end{array}$ & $\begin{array}{l}.39 \\
.81\end{array}$ & $\begin{array}{l}.34 \\
.61\end{array}$ & $\begin{array}{l}.42 \\
.72\end{array}$ & $\begin{array}{l}.31 \\
.72\end{array}$ \\
\hline
\end{tabular}

$F(12,80)=4.15, p<.005$. The analysis performed on the data from the normal subjects resulted in a nonsignificant effect for the type of CS condition, $F(3,44)=.38$, but did reveal significant effects for the trials blocks variable, $F(4,176)=24.33, p<.001$, as well as for the Type of CS by Trial Blocks interaction, $F(12,176)=2.01, p<.05$. The significant type of CS by Trial Blocks interaction appeared to be due to the variability in the curves over trials and not to any differential trends associated with a particular CS condition.

Since it appeared that the retardates fell into two distinct conditioning performance groups, frequency distributions for the normal and retardate groups showing the percentage of subjects falling into each of five class intervals of percentage CRs on the last 50 conditioning trials were determined as shown in Figure 1. A Kolmogorov-Smirnov two-sample test revealed a significant difference between the two distributions, $\mathrm{D}=.500, \mathrm{p}<.001$. Of the 10 retarded subjects who fell into the $81 \%-100 \%$ interval, three had received a speech sound CS, two a slow rise-time tone, three a fast rise-time tone (tape) and two a fast rise-time tone (oscillator). Four of the retarded subjects who had participated in previous trace classical conditioning studies were "good" conditioners in this study while the remaining six were "poor" conditioners.

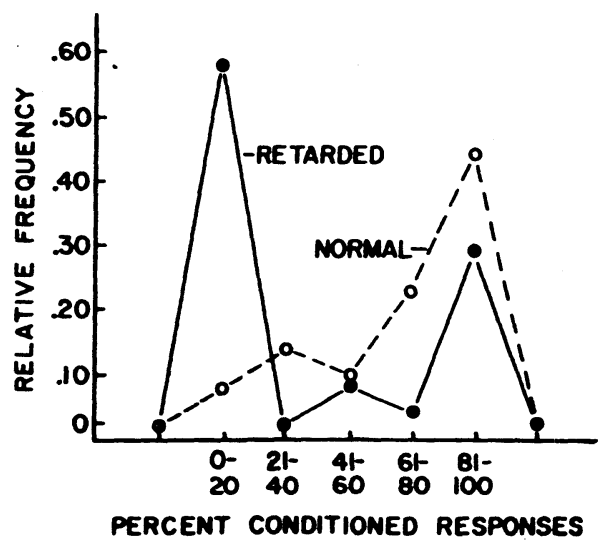

Figure 1. Relative frequency distributions for the retardate and normal groups as a function of percent conditioned response on the last 50 conditioning trials. 


\section{DISCUSSION}

The results of the present study indicate that a speech sound CS is no more effective than a pure tone CS in the trace conditioning of retardates when a $450-\mathrm{msec}$ empty trace interval is employed. While accepting the null hypothesis can be dangerous with small samples, the data do suggest that a speech sound CS does not produce any dramatic increase in retardate trace-conditioning performance.

Since only fast rise-time stimuli had been utilized in the previous eyelid conditioning studies which demonstrated the retardate stimulus trace deficit, and since there is evidence of superior differential conditioning in normals with slow rise-time CSs, there was a possibility that a slow rise-time tone would in some manner facilitate retardate trace conditioning. This did not prove to be the case, however, since there was little indication of a slow vs. fast rise-time effect.

The higher levels of conditioning demonstrated by the normal subjects, as evidenced by their superior performance following a single conditioning session as compared to the retardates' performance after five sessions, was expected on the basis of previous data. What was not expected, however, was the bimodal distribution of retardate performance in which a minority of the retardates showed very good conditioning by the end of the 250 trials while the majority showed little if any conditioning.

It is unclear what individual difference factors were operating to differentiate the retarded subject's trace conditioning performance. The possibility was considered that terminal conditioning might be a function of drug intake, however inspection of the subjects' medical charts did not support such a conclusion, or give other indications of individual difference factors that might be responsible for the conditioning differences. Similarly, there was no apparent relationship of MA to level of conditioning, and a correlation between these two factors was nonsignificant.

It is possible that individual differences in CNS integrity in terms of the subject's type and degree of organicity (Ross \& Ross, 1973) is related to trace-conditioning performance, particularly as it relates to the strength and decay characteristics of the CS trace. Given the presumed relationship between orienting response characteristics and the retarded and the hypothesized relationship of orienting behavior to conditioning, it is also possible that the bimodal distribution of conditioning performance could reflect differences in the orienting response characteristics of the good and poor conditioners.

\section{REFERENCES}

Mattingly, I. G., Liberman, A. M., Syrdal, A. K., \& Halwes, T. Discrimination in speech and nonspeech modes. Cognitive Psychology, 1971, 2, 131-157.

Nelson, M. N. \& Ross, L. E. Effects of masking tasks on differential eyelid conditioning: A distinction between knowledge of stimulus contingencies and attentional or cognitive activities involving them. Journal of Experimental Psychology, 1974, 102, 1-9.

Ross, L. E., \& Ross, S. M. Classical conditioning and intellectual deficit. In D. K. Routh (Ed.), The experimental psychology of mental retardation. Chicago: Aldine, 1973.

Ross, S. M. Trace and delay classical eyelid conditioning in severely and profoundly retarded subjects as a function of interstimulus interval. American Journal of Mental Deficiency. 1972, 77, 39-45.

Ross, S. M., \& Ross, L. E. Comparison of trace and delay classical eyelid conditioning as a function of interstimulus interval. Journal of Experimental Psychology, 1971, 91, 165-167.

Ross, S. M., \& Ross, L. E. Stimulus input recruitment and stimulus trace decay factors in the trace conditioning deficit of severely retarded young adults. American Journal of Mental Deficiency, 1975, 80, 109-113.

Wilcox, S. M., \& Ross, L. E. Differential classical eyelid conditioning as a function of CS intensity, CS rise time, and interstimulus interval. Journal of Experimental Psychology, $1969,82,272-278$

(Received for publication October 30, 1975.) 